\title{
MEDIAÇÃO TECNOLÓGICA E PROCESSO EDUCACIONAL EM TEMPOS DE PANDEMIA DA COVID-19
}

\author{
MEDIACIÓN TECNOLÓGICA Y PROCESO EDUCACIONAL EN LOS TIEMPOS DE \\ PANDEMIA DEL COVID-19
}

\author{
TECHNOLOGICAL MEDIATION AND EDUCATIONAL PROCESS IN TIMES OF \\ COVID-19 PANDEMIC
}

\author{
Eucídio Pimenta ARRUDA ${ }^{1}$ \\ Suzana dos Santos GOMES ${ }^{2}$ \\ Durcelina Ereni Pimenta ARRUDA ${ }^{3}$
}

RESUMO: A pandemia da Covid-19 provocou no Brasil e no mundo mudanças repentinas nos campos social, político, econômico e educacional. Dentre as medidas implementadas, o isolamento social implicou no fechamento das escolas, que passaram a ser desafiadas a assumirem o ensino remoto emergencial, mediado pelas tecnologias digitais. Nesse sentido, pretendeu-se com este estudo verificar como a escola pode cumprir a sua função políticosocial no contexto da crise da pandemia. Quanto à metodologia, trata-se de um estudo exploratório de abordagem qualitativa que envolveu o uso de dados secundários e empíricos da Unesco e, ainda, a realização de um levantamento que mapeou a maneira como os estados no Brasil estão conduzindo as atividades escolares. Os resultados atestam que a pandemia da Covid-19 exerce impactos diferenciados na vida social e que a oferta do ensino remoto pelos estados tem sido encaminhada por meio de diferentes propostas; entretanto, verificou-se que, de modo geral, as iniciativas governamentais não têm promovido efetivamente a participação da comunidade escolar.

PALAVRAS-CHAVE: Pandemia Covid-19. Escola. Mediação tecnológica.

RESUMEN: La pandemia de Covid-19 ha provocado en Brasil y en el mondo cambios repentinos en los campos social, político, económico y educacional. Dentro las medidas implantadas, el aislamiento social ha implicado en el cierre de las escuelas, que pasaran a ser desafiadas a asumir la enseñanza remota de emergencia, mediada por las tecnologías digitales. En eso sentido, pretendemos con este estudio verificar: ¿Como la escuela pode cumplir su función político-social en el contexto de la crisis de la pandemia? Con respecto a

\footnotetext{
${ }^{1}$ Universidade Federal de Minas Gerais (UFMG), Belo Horizonte - MG - Brasil. Professor e Pesquisador do Programa de Pós-Graduação em Educação: Conhecimento e Inclusão Social. Doutorado em Educação (UFMG). ORCID: https://orcid.org/0000-0002-9201-6530. E-mail: eucidio@gmail.com

${ }^{2}$ Universidade Federal de Minas Gerais (UFMG), Belo Horizonte - MG - Brasil. Professora e Pesquisadora do Programa de Pós-Graduação em Educação: Conhecimento e Inclusão Social. Pós-Doutorado pela Universidade de Lisboa (UL) e Universidade de São Paulo (USP). ORCID: https://orcid.org/0000-0002-8660-1741. E-mail: suzanasgomes@fae.ufmg.br

${ }^{3}$ Universidade Federal de Minas Gerais (UFMG), Belo Horizonte - MG - Brasil. Professora do Programa de Mestrado Profissional Educação e Docência (FaE/UFMG). Pós-Doutorado em Educação pela Universidade Federal de Minas Gerais (UFMG). ORCID: https://orcid.org/0000-0003-1514-3461. E-mail: durcelina@gmail.com
} 
la metodología, tratase de un estudio exploratorio de abordaje cualitativo que envolvió el uso de datos secundarios y empíricos de Unesco y, además, la realización de un levantamiento que ha mapeado a la manera como los estados Brasileños están conduciendo las actividades escolares. Los resultados atestan que la pandemia de Covid-10 ejerce impactos diferenciados en la vida social y que la oferta de la enseñanza remota entre los estados ten sido encaminada por medio de diferentes propuestas; todavía, hemos verificado que de modo general, as iniciativas gubernamentales non tiene promovido efectivamente la participación de la comunidad escolar.

PALAVRAS-CLAVE: Pandemia Covid-19. Escuela. Mediación tecnológica.

ABSTRACT: The Covid-19 pandemic caused sudden changes in the social, political, economic, and educational fields in Brazil and worldwide. One of the measures implemented is the shutdown of schools during physical isolation, which challenged them to assume distance learning on an emergency basis, mediated by digital technologies. In this sense, this article aimed to analyze how the school can fulfill its political and social function in the context of the pandemic crisis. From the methodological point of view, it is an exploratory study with a qualitative approach with secondary and empirical data from UNESCO. There was also a mapping of Brazilian states on the conduct of education during the coronavirus pandemic. The results indicate that the new coronavirus pandemic has had different implications for social life; emergency remote education implemented in most Brazilian states did not count on the participation of the school community.

KEYWORDS: Covid-19 pandemic. School. Technological mediation.

\section{Introdução}

O contexto atual marcado pela pandemia da Covid-19 tem provocado no Brasil e no mundo uma série de efeitos nos campos social, político, econômico e educacional. Dentre as ações para conter/minimizar a propagação do vírus, o Ministério da Saúde (MEC) e as autoridades governamentais decretaram o isolamento social, o que implicou no fechamento de escolas e universidades. Essa decisão tem provocado alguns questionamentos, entre eles: quais são as consequências do fechamento das escolas? Isolamento social ou isolamento físico? Qual o papel da escola e o que ela pode promover no contexto de crise? Que contribuições podem ser dadas pela escola no enfrentamento da pandemia? Que ações poderão ser implementadas na pandemia e no pós-pandemia pelos governos estaduais brasileiros?

Trata-se de um cenário complexo que demanda um resgate da função social da escola, o reconhecimento da sua relevância na sociedade em tempos de crise, a compreensão de que o isolamento deverá ser físico e não social; e, ainda, a abertura para revisitar o papel da escola 
frente aos desafios enfrentados na sociedade contemporânea, entendendo que a escola não poderá permanecer alheia ao que acontece no Brasil e no mundo.

Para além da perspectiva da escola em seu caráter institucional, é necessário também lançar olhares sobre as políticas educacionais que emergem em caráter emergencial em todos os países do mundo. Dados do Fundo das Nações Unidas para a Infância - Unicef (2020) demonstram que $90 \%$ de jovens permanecem sem acesso à escola, devido ao isolamento social.

Verificou-se, ainda, inúmeros desafios para planejar a reabertura das escolas, sobretudo em função da alta taxa de propagação da Covid-19, que tem levado a maioria dos países a adotarem medidas de educação remota, mediada por tecnologias digitais. Sob esse aspecto, pretende-se nesse artigo compreender de que forma se dá a implantação dessas políticas, a fim de responder às questões: qual o nível de participação da comunidade escolar nas decisões sobre retorno remoto nas iniciativas dos governos estaduais brasileiros? Como a escola pode cumprir a sua função político-social no contexto de crise da pandemia da Covid$19 ?$

É pertinente a compreensão desses aspectos, pois as ações didático-pedagógicas são influenciadas pelos modelos de educação mediada por tecnologias implementadas. Ele pode ser um modelo massivo, no qual um órgão central é responsável pela disseminação dos conteúdos escolares; pode conter elementos de descentralização informativa, na medida em que permite o uso de aplicativos de acesso direto entre professores e comunidade escolar (redes sociais, chats exclusivos etc.), ou pode ser um modelo em rede, no qual os microuniversos das escolas desenvolvem procedimentos didáticos construídos pela aproximação subjetiva. Nesse último, os sujeitos emergem como participantes ativos no processo de produção do conhecimento, na medida em que se conectam e constroem saberes coletivamente.

Constata-se que as relações entre os modelos de educação remota e os sujeitos envolvidos com e no processo educativo revelam o tipo de expectativa da escola na vida dos envolvidos, bem como indicam caminhos e possibilidades para se pensar a educação em um contexto de pós-pandemia.

Nesse sentido, pesquisas sobre o papel da escola, entre elas, Monteiro (2020); Pereira, Narduchi e Miranda (2020) afirmam que a sociedade e a escola não serão mais as mesmas após a crise da Covid-19. Pode-se afirmar que compreender essa transformação é importante para os sujeitos que discutem e desenvolvem as práticas escolares. Como se vê, a crise de saúde pode enunciar também uma crise educacional de grandes proporções, na medida em 
que o distanciamento físico provisório venha a se configurar em distanciamento permanente dos estudantes, a ser objeto de estudo em pesquisas futuras pós-pandemia.

\section{Procedimentos teórico-metodológico}

Nesse tópico apresenta-se o percurso metodológico adotado que culminou, dentre outras ações, com a escrita desse artigo. No que diz respeito à metodologia, optou-se pela pesquisa exploratória de abordagem qualitativa organizada em duas etapas: a primeira consistiu no uso de dados secundários e empíricos, sendo parte destes extraídos do site da Organização das Nações Unidas para a Educação, a Ciência e a Cultura - Unesco (2020) Trata-se de uma pesquisa realizada com estudantes, pais e professores do mundo inteiro sobre as seguintes questões: escola e universidades estão fechadas: como você lida com isso? ${ }^{5} \mathrm{O}$ aprendizado nunca para - depoimentos de estudantes, pais e professores ${ }^{6}$.

Com base nas contribuições da Unesco (2020), considerou-se relevante aplicar a pesquisa no Brasil, especificamente em Minas Gerais, estado em que os pesquisadores atuam, exercendo atividades de ensino, pesquisa e extensão. Para tanto, as questões foram enviadas via correio eletrônico ao público-alvo residente no estado. Do total de 60 e-mails enviados retornaram 37 respostas; estas foram lidas e categorizadas. Tendo em vista os limites desse artigo, apresentam-se alguns depoimentos que foram selecionados. Assim, foram utilizados como critérios: a autorização de publicação dos depoimentos pelos participantes; o envio da resposta dentro do prazo solicitado, e a seleção diversificada de munícipios do estado.

A segunda etapa, caracterizada como estudo exploratório, consistiu na revisão de literatura realizada nas bases de dados brasileiras do Scielo e no portal de periódicos da Capes no período de março a agosto de 2020 , que se deu por meio da combinação dos seguintes descritores: pandemia Covid-19; função político-social da escola e mediação tecnológica, a fim de verificar como a temática tem sido abordada pelos pesquisadores do campo da educação. Ainda nessa parte, realizou-se um levantamento que objetivou mapear como os estados no Brasil estão conduzindo as atividades escolares no contexto da pandemia do coronavírus.

\footnotetext{
${ }^{4}$ Disponível em: https://en.unesco.org/. Acesso em: 22 abr. 2020.

${ }^{5}$ Disponível em: https://pt.unesco.org/covid19/educationresponse/learningneverstops. Acesso em: 22 abr. 2020.

${ }^{6}$ Disponível em: https://en.unesco.org/covid19/educationresponse/learningneverstops/testimonies. Acesso em: 22 abr. 2020.
} 
Nesse sentido, as informações coletadas foram: adesão ou não das 27 redes estaduais e uma rede distrital de educação à educação remota emergencial; tipos de mídias utilizadas no modelo de educação remota; indícios de participação da comunidade escolar na definição do modelo de retorno escolar emergencial; análise sobre o atendimento à equidade e garantia de acesso às opções de materiais a todos os estudantes das respectivas redes e, por fim, uma análise preliminar sobre os dados de acesso dos estudantes aos materiais disponíveis pelas respectivas redes públicas de educação analisadas.

Finalmente, na análise dos dados utilizou-se como referência as contribuições de Bardin (2011), cujo tratamento envolveu: a pré-análise, a exploração do material, e a inferência e interpretação dos resultados.

\section{O que dizem e pensam estudantes, pais e professores sobre a pandemia da Covid-19?}

Neste tópico apresentam-se os dados secundários da pesquisa realizada pela Unesco (2020) e divulgada em seu site institucional sobre as consequências adversas do fechamento das escolas e universidades provocadas pela Covid-19 no mundo. Nessa proposta, estudantes, pais e professores compartilham suas histórias sobre como estão lidando e continuam aprendendo durante o fechamento das escolas. Assim, tendo como referência o levantamento realizado pela Unesco (2020), considerou-se relevante ampliar a consulta em Minas Gerais, a fim de obter dados da comunidade educativa sobre as repercussões da pandemia no país. A escolha desse estado se justifica pelo fato dos pesquisadores terem projetos de pesquisa e de extensão em andamento nas escolas da rede estadual.

Perguntados sobre o fechamento das escolas, alguns estudantes em seus depoimentos revelaram que,

Nossa escola foi fechada, mas nosso professor criou um canal no aplicativo Telegram para enviar nossa lição de casa e nos explicar as aulas. É uma boa alternativa, mas eu sinto muita falta de ir à escola, de nossos professores e de meus amigos. (Teeba, estudante, Bagdá, Iraque).

Enquanto as escolas estão fechadas, eu e meus irmãos estamos usando nosso tempo livre juntos para fazer muitas coisas criativas. Fora isso, estamos fazendo cursos online para que possamos estudar em casa, uma vez que não podemos ir à escola. (Marietta, estudante, Grécia).

Este cenário de pandemia demonstra o tamanho da desigualdade presente no Brasil, principalmente no ensino. Várias escolas públicas não estão ofertando aulas online e estão totalmente paradas. Essa situação difere das escolas privadas que estão oferecendo aulas online, sem contar que vários alunos de escolas públicas também não têm acesso a computadores $e$ 
celulares, o que dificulta o ensino em casa. Caberia ao governo federal, estadual e até municipal tentar diminuir esse problema. [...] o que fica nítido é que os alunos de escolas públicas vão sofrer muito mais com essa pandemia comparado aos alunos da rede privada. (Leonardo, estudante, Belo Horizonte, MG).

Como se vê, os depoimentos dos estudantes atestam a relevância da escola e dos professores. Para muitas crianças, adolescentes e jovens a escola é espaço de interação, do diálogo e da aprendizagem. Os professores são referência, influenciam e inspiram comportamentos, atitudes e, consequentemente, projetos de vida. (MONTEIRO, 2020; BADIN; PEDERSETTI; SILVA, 2020).

Pode-se afirmar que, no contexto da pandemia da Covid-19, muitos professores estão presentes, interagindo com os estudantes, gravando aulas, preparando atividades de modo síncrono e assíncrono. (MONTEIRO, 2020; UNESCO, 2020; XIAO; LI, 2020). Porém, essas atividades estão sendo ofertadas, de modo geral, principalmente para os estudantes da rede privada. O depoimento do Leonardo destaca a desigualdade social presente no Brasil. Enquanto estudantes da rede privada aprendem por meio de diferentes recursos, muitos estudantes da rede pública não têm acesso à internet e, portanto, estão privados dessas oportunidades de aprendizagem.

Os pais também manifestaram sobre o fechamento das escolas; para eles,

Prezo pela educação dos meus netos, pois não tive oportunidade na vida de estudar e hoje avalio que faz muita falta. Em casa, procuro estimular todos a estudar por meio de livros e internet. Vejo que no momento este é o único meio de ensiná-los. (Teresinha, avó, Betim, MG).

Sou pai e professor e tenho realizado aulas em casa, acredito que a contribuição maior é afetiva, uma forma de manter ativa a relação professor e aluno. No que diz respeito ao aspecto educacional e avaliativo existem perdas. Meu filho faria Enem esse ano, percebo que as aulas em casa não estão suprindo suas demandas. (Hugo, pai e professor, Vespasiano, MG).

Estou vivendo preocupado e inseguro com o futuro, procuro me adaptar a cada dia que passa, pois foi um fato inédito que causou grande impacto na vida das pessoas e na escola, com certeza está trazendo amadurecimento das relações no convívio familiar. (Fernando, pai, Ibirité, MG).

O que me preocupa é o modo pelo qual o atual governo atua nesta situação. Não há uma reflexão profunda sobre o impacto da pandemia sobretudo para os alunos das classes populares. E de maneira irresponsável autoriza aulas remotas, sem resguardar princípios básicos: universalização, igualdade de condições e qualidade [...]. (Miryam, mãe, São Joaquim de Bicas, MG). 
Nessa crise sem precedentes, os pais tiveram que aprender a lidar com a imprevisibilidade, preservando acima de tudo a vida. Assim, os depoimentos dos pais revelam que a pandemia demandou mudanças de comportamentos e impactaram diretamente no convívio social e familiar. Os pais foram desafiados a escolarizar os filhos em casa. No entanto, não receberam orientação e suporte para realizar esta tarefa complexa. $\mathrm{O}$ depoimento de Myriam chama atenção para o princípio da Constituição Federal de 1988 (BRASIL, 1988), artigo 205, "a educação é direito de todos e dever do Estado e da família", mesmo em tempos de pandemia.

Um dos desafios da educação nesse contexto é a abertura de amplo debate com a comunidade escolar sobre as soluções apresentadas para a crise sanitária. Nesse sentido, as atividades remotas e/ou atividades pedagógicas encaminhadas por meio de plataformas digitais ou redes sociais podem ser alternativas relevantes, desde que seja garantido o acesso à internet e que tais atividades sejam planejadas atendendo às demandas pedagógicas, psicológicas e afetivas dos estudantes. Também é necessário que o governo federal e as esferas estaduais e municipais invistam na educação a fim de garantir ensino de qualidade para todos.

Para os professores,

A propagação do coronavírus levou à perda de um ano escolar e à perda dos esforços dos estudantes. É imperativo que todos nós desempenhemos nossos papéis para garantir educação aos nossos estudantes remotamente. (Faten, diretor de escola, Iraque).

Como professor, eu incentivo os estudantes de todo o mundo a se animarem e espero que possamos superar isso. Estou fazendo tudo o que é preciso para ensinar os estudantes e a população em geral sobre as medidas a serem tomadas para se protegerem deste virus mortal. (Paul, professor, Quênia).

O impacto da quarentena ainda não foi devastador para os nossos estudantes. Nós temos uma equipe extremamente dedicada, que está trabalhando diariamente de casa e criando uma sala de aula virtual colaborativa. (Marieta, professora, Espanha).

Eu sou professor na rede estadual e estou em casa devido ao isolamento social. Não está sendo fácil, estamos inseguros [...]. Na escola onde atuo a pandemia interrompeu tudo. A crise é geral, temos um governo que não valoriza a educação e nem os seus profissionais. Estamos vivendo momentos dificeis e muitas vezes nos sentimos desmotivados [...]. (Darlan, professor, Santa Luzia, MG).

A paralisação das aulas nas escolas e nas universidades em decorrência da Covid-19 não afeta igualmente os estudantes, há realidades e contextos sociais, culturais e econômicos que revelam situações discrepantes e, 
porque não, antagônicas. Sou professora da educação básica e estou vivenciando situações distintas relacionadas ao meu trabalho. De um lado, a educação privada, na qual sou mediadora entre a plataforma de ensino online e os alunos. Recentemente, o governo começou a implementar aulas remotas. As aulas são gravadas e repassadas por uma rede de televisão, sem que sejam observadas as especificidades das escolas e dos alunos. Em suma, a pandemia, aliada a paralisação das aulas, contribuiu para aumentar o abismo educacional existente entre o ensino privado e o público, ampliando ainda mais as desigualdades tão presentes em nosso pais. (Glícia, professora, Belo Horizonte, MG).

Também os professores revelam em seus depoimentos que a pandemia da Covid-19 imprimiu um sentido de urgência nunca vivenciado na história recente. A suspensão da rotina escolar que envolve, entre outros, relação professor e estudante, interação entre pares, atividades pedagógicas, tem levantado o debate sobre o papel da escola durante a pandemia e no pós-pandemia (ESTELLÉS; FISCHMAN, 2020).

Nesse sentido, esse contexto reafirma o papel social da escola para o desenvolvimento de competências socioemocionais, com base nos princípios norteadores presentes na Constituição Federal de 1988 (BRASIL, 1988), na Lei de Diretrizes e Bases da Educação Nacional - LDB n. 9.394/1996 (BRASIL, 1996) e na Base Nacional Comum Curricular BNCC (BRASIL, 2017; 2018). Uma das possibilidades para a escola manter-se presente seria por meio das aulas remotas emergenciais (ARRUDA, 2020). O professor poderia se tornar presente junto aos estudantes a fim de motivá-los, despertando esperança na superação da crise. O diálogo humanizado é pedagógico e, ainda, habilidades, competências e atitudes não são apreendidas em aulas expositivas, estas são adquiridas a partir de vivências. Torna-se relevante destacar que gestores e coordenadores pedagógicos podem atuar estimulando o compromisso e a motivação docente, condições fundamentais em tempos de crise para o bemestar docente e garantia da qualidade do trabalho pedagógico promovido junto aos estudantes.

Como indicado nos depoimentos de Faten e Paul, o modo pelo qual o professor constrói a interlocução com os estudantes será decisivo nesse contexto. Torna-se relevante garantir acolhida, integridade e saúde mental. No contexto da pandemia, uma das prioridades da escola é garantir sobrevivência e cuidado. Por esse motivo, pensar projetos educativos que partam dos problemas vividos pode ser uma alternativa relevante (COUTO; COUTO; CRUZ, 2020).

Como se vê, Darlan e Glícia atuam em escolas da rede pública no Brasil e revelam em seus depoimentos aspectos da crise provocada pela pandemia, que evidenciam, entre outros, as condições de trabalho nas escolas da rede pública. Pode-se afirmar que a escola é o único espaço de aprendizagem seguro e acessível para percentual significativo de estudantes da rede 
pública. Por mais precária que sejam, as escolas e seus professores ainda são os que acolhem, identificam problemas e fazem com que eles acreditem que podem ser alguém.

Torna-se relevante destacar que dados da Pesquisa Nacional por Amostra de Domicílios Contínua - PNAD contínuo de 2018 mostram que cerca de $20 \%$ de estudantes das escolas públicas não têm acesso à internet, e metade não possui computador, tampouco espaço adequado em casa para estudo. O governo terá que considerar e corrigir esse problema para não deixar à margem da educação uma enorme parcela de estudantes, do contrário as desigualdades sociais serão acirradas.

E, ainda, defende-se políticas públicas que invistam no ensino online, acessível a todos. Para tanto será importante: acesso a computadores e internet; formação inicial e continuada de professores no campo das tecnologias digitais; planejamento de atividades adequadas para esse contexto, assegurando monitoramento e avaliação das propostas pedagógicas.

Na segunda questão, estudantes, pais e professores foram convidados a compartilhar suas experiências sobre como estão lidando e continuam aprendendo durante o fechamento das escolas e universidades pela Covid-19.

Alguns depoimentos relatam que,

Ultimamente, a vida cotidiana das pessoas mudou rapidamente, desde que a Covid-19 começou a se expandir em todo o mundo. Portanto, foi decidido que algumas medidas muito drásticas deveriam ser tomadas em beneficio da humanidade. Essas medidas, porém, perturbaram toda a população do mundo. Escolas e universidades foram fechadas e isso afetou a educação dos alunos. No entanto, com o uso das tecnologias e das plataformas online, as coisas se tornaram mais fáceis. [...] muitas pessoas não percebem o perigo. Como consequência, o vírus se expande rapidamente. Nos países vizinhos, os casos e mortes pelo vírus continuam aumentando. [...] (Vivian, estudante, Grécia).

Também está claro que as crianças em idade escolar são duramente atingidas pelo bloqueio em muitos países devido à pandemia da Covid19. Dói ver as crianças perderem a oportunidade de obter educação. Os professores também ficam tristes ao ver seus alunos fora da escola, com medo e incerteza de quando [irão] retomar as aulas. Como professor, incentivo os alunos do mundo inteiro a se animarem e terem esperança de que possamos superar essa crise. Estou tomando todas as medidas necessárias para educar os alunos e a população em geral sobre as medidas a serem tomadas para se proteger desse vírus mortal. Utilizo as mídias sociais e outras plataformas online para criar consciência sobre a pandemia. [...]. (Paul, professor, Quênia).

Nesta semana as aulas da minha filha retornaram. Fico angustiado porque não tenho condições para auxiliá-la. Tenho apenas o ensino fundamental II, na época abandonei a escola para trabalhar. Também avalio que o 
ambiente doméstico é diferente do ambiente escolar. Minha filha é inteligente, mas está dispersa. Sente falta de acompanhamento escolar. Estou preocupado pois vejo que ela não atingirá o esperado na aprendizagem. (Aguinaldo, pai, Rio Acima, MG).

Os depoimentos de Vivian, Paul e Aguinaldo destacam a relevância do uso das tecnologias digitais pela escola. Pensar as tecnologias digitais para aprender implica entender que as tecnologias não vão revolucionar o ensino e a escola, mas o modo como as tecnologias são utilizadas para a interação entre estudantes e professores pode significar novas oportunidades de aprendizagem. Ou seja, a evolução dos processos de interação e comunicação no ensino depende das pessoas envolvidas no processo (COSCARELLI, 2016; GOMES, 2016; RIBEIRO, 2016).

Coerente com essa perspectiva, ao elaborar projetos de ensino nas redes digitais, é importante lembrar que professores e estudantes são sujeitos socioculturais e aprenderão melhor envolvidos em um sistema cooperativo, baseado em trocas de conhecimentos, saberes e práticas (NOVAIS, 2016).

Torna-se relevante destacar que o interesse pela aprendizagem coletiva que se dá por meio remoto aumenta a responsabilidade dos professores e estudantes, exigirá ir além das informações disponibilizadas, buscar novos conhecimentos, problematizar questões e socializar descobertas.

Outros professores revelaram que,

Ao longo do isolamento social neste periodo de pandemia foram ofertados cursos, lives, palestras e outras formas de compartilhamento utilizando a internet $e$ as redes sociais. Escolas mantiveram seus professores ministrando aulas por webconferências, facebook, whatsapp e outros canais digitais. Assim, o aprendizado não parou. Tomando-se o devido cuidado com o acesso às informações divulgadas para que, de fato, se tornem conhecimentos para o contínuo desenvolvimento dos sujeitos. (Maria Aparecida, professora, Lagoa Santa, MG).

A aprendizagem é constante e, devido ao isolamento, temos a oportunidade de intensificar nossas relações familiares, afetivas, emocionais, refletir sobre saberes constituintes de nossa identidade. Uma pena os donos do capital, os governantes brasileiros (salvo algumas exceções) não se preocuparem com a vida em primeiro lugar, mas sim com os lucros. Há uma estúpida dicotomia, falso dilema criado entre economia e vida, como se fosse possivel separar essas coisas. Se tivéssemos um sistema no qual a vida fosse mais importante as pessoas poderiam receber mais acolhimento via políticas públicas. (Alex, professor, Contagem, MG).

Para os professores Maria Aparecida e Alex, a aprendizagem é contínua. A pandemia da Covid-19 tem imposto uma ampla gama de desafios de ordem política, econômica, social e 
educacional. Nesse contexto de incertezas e inseguranças, estudantes, pais e professores estão reinventando ações e práticas.

No Brasil, estes desafios ganham contornos complexos, tendo em vista que milhões de pessoas vivem na pobreza. $O$ isolamento físico provocou a suspensão das atividades econômicas e aumentou a fragilidade da rede de proteção social. Para uma parcela significativa da população os efeitos produzidos pelo isolamento são graves e irreversíveis.

Como se vê, é nesse contexto marcado pela crise que a educação e a escola entendida como direito devem atuar; dentre as possibilidades é urgente ampliar o alcance da intervenção educacional a fim de eliminar/minimizar os efeitos da pandemia.

Diante do exposto, pode-se afirmar que a aprendizagem é contínua e é necessária como ação construída na interação mediada pelo outro. As redes sociais e as tecnologias digitais quando disponíveis poderão favorecer esse processo que demanda, entre outros, ressignificar o papel da escola, valorizar os profissionais da educação, garantindo o processo educativo em defesa da vida (GOMES; TAVARES; MELO, 2019).

\section{Dimensões da continuidade das práticas escolares no contexto da Covid-19 mediadas por tecnologias digitais}

A Covid-19 trouxe um fato inédito na história desde a constituição, em nível mundial, da instituição escolar como referência da formação de novas gerações: em meados de abril deste ano, pela primeira vez, mais de 90\% dos estudantes de 188 países foram impedidos de frequentar as instituições escolares devido à necessidade do isolamento físico. Em junho observava-se ainda $63 \%$ dos estudantes de 129 países fora da escola devido à crise sanitária, de acordo com dados da Unesco (2020).

Sob o ponto de vista histórico, a sociedade costuma adequar-se às diferentes crises com os saberes que lhes são contemporâneos - ou seja, os equipamentos disponíveis para uso e apropriação.

Ressalta-se que na sociedade contemporânea existem tecnologias digitais de informação e comunicação (TDIC) que possuem alcance global e que se tornaram centro de debates como possibilidades para apoio para romper o isolamento físico. Dados da Organização das Nações Unidas (ONU, 2020) sobre a Educação revelam que a maioria dos países definiram como política de manutenção das atividades escolares o uso das TDIC.

Na pesquisa digital realizada foram consultados vários países para tentar compreender de que forma as TDIC foram incorporadas e apropriadas. Ao estabelecer uma comparação 
com o Brasil, foi possível identificar diretrizes nacionais na condução de respostas educacionais à crise da Covid-19. A pesquisa envolveu os seguintes países: Portugal, Espanha, Estados Unidos, Itália, Alemanha, Reino Unido, China, Austrália, Chile, México, Uruguai e Argentina.

Verificou-se que estes países tinham em comum respostas educacionais em nível nacional, com diretrizes para pais, professores e comunidade escolar sobre os procedimentos para manterem a conexão da escola com os estudantes. No entanto, o Brasil destacou-se pela inexistência de uma orientação nacional do sistema educacional para a crise da Covid-19, revelando, entre outros aspectos, a falta de liderança; a inexistência de políticas nacionais do Ministério da Educação (MEC), sob o governo do presidente Jair Bolsonaro.

\title{
A educação remota emergencial
}

O termo "educação remota emergencial" foi identificado em inúmeras iniciativas de países. De acordo com Hodges et al. (2020), a educação remota online digital diverge da Educação a Distância $(\mathrm{EaD})$, pois ela propõe usos e apropriações de tecnologias de modo específico para o atendimento escolar no contexto da educação presencial.

Apesar de ambas pressuporem a mediação tecnológica nos processos de ensinar e aprender, Arruda (2020, p. 265) considera que,

\begin{abstract}
A EaD envolve planejamento anterior, consideração sobre perfil de aluno e docente, desenvolvimento a médio e longo prazo de estratégias de ensino e aprendizagem que levem em consideração as dimensões síncronas e assíncronas da $\mathrm{EaD}$, envolve a participação de diferentes profissionais para o desenvolvimento de produtos.
\end{abstract}

Para Hodges et al. (2020), a educação remota emergencial não possui tais propriedades, pois trata-se de uma resposta à crise da Covid-19 que altera o modo de acesso aos conteúdos curriculares para uma forma alternativa à educação presencial, em tempos e planejamentos distintos.

Os modelos de $\mathrm{EaD}$ ou de educação remota emergencial são diversos, no sentido de integrarem ou não tecnologias digitais e/ou tecnologias analógicas e também no sentido de envolverem uma perspectiva didático-pedagógica massiva ou dialógica.

O modelo de uso apenas de tecnologias digitais não garante equidade, pois, segundo dados da Unesco (2020), existem milhões de jovens sem acesso adequado aos computadores e à internet. Espera-se que sob uma perspectiva de emergência, na qual não é possível resolver imediatamente problemas estruturais históricos, as tecnologias analógicas sejam integradas para garantir que um percentual significativo de jovens tenha acesso à escola. Coerente com 
essa perspectiva, as tecnologias analógicas podem envolver transmissão de TV, rádio convencional e material impresso.

No caso dos modelos didáticos massivos e dialógicos, o primeiro pressupõe uma organização por meio de transmissão centralizada por um órgão educacional e distribuído para milhares ou milhões de pessoas. Ainda que sejam abertas opções de diálogo, como comentários em páginas de Youtube, por exemplo, não é dialógico, pois não existem professores realizando o acompanhamento de estudantes em uma ferramenta que apresenta milhares de comentários simultâneos.

A perspectiva dialógica envolve inúmeras tecnologias para compartilhamento de materiais didáticos, mas o modo de transmissão envolve o professor que acompanha seus estudantes. Nesse modelo, o professor acompanhará suas turmas presenciais originais e tornase o interlocutor do material didático junto aos estudantes. Um dos aspectos positivos nesse tipo de abordagem é que ele diminui a chance de o estudante desconectar-se da aula remota com um clique, de acordo com Bauman (2018), desvinculando-se do outro ou de um conteúdo acessado pelas redes digitais.

Entretanto, esse modelo pressupõe que o corpo docente de uma rede tenha preparo técnico e pedagógico para trabalhar a distância. Para Arruda (2018), a maioria dos docentes dos países da Organização para a Cooperação e Desenvolvimento Econômico (OCDE) não tiveram acesso a uma formação adequada para trabalhar com tecnologias digitais. Também Gatti (2010) afirma que no Brasil os currículos de formação de professores não envolvem sequer $1 \%$ de sua carga horária total para a formação tecnológica do docente. No contexto da pandemia, Gatti (2020, p. 32) identificou desafios a serem superados, entre eles, "as condições e formação dos docentes para trabalho de educação escolar em modo remoto e para uso de mídias, para o desenvolvimento de formas de envolvimento ativo dos estudantes", entre outros. Assim, ambos os autores encontraram inúmeros obstáculos na implementação de educação remota quando estavam em situação de isolamento total.

Como se vê, os dados ora apresentados atestam que a Covid-19, se por um lado afeta a escola de forma intensiva e não planejada, por outro, pode transformar a escola e seus sujeitos, na medida em que exigem que se repense os usos e as formas de apropriação das tecnologias devido às experiências vivenciadas no período da pandemia.

\section{Experiências com Educação Remota Emergencial no Brasil: análises preliminares}


Verificou-se, por meio do estudo realizado, que no Brasil não há uma política nacional a respeito da implementação de ações para amenizar o isolamento físico da comunidade escolar. Para Arruda (2020) e Monteiro (2020) o MEC tem gerado mais conflitos do que proposto soluções, e se ausentado dessas discussões. Optou-se então por uma análise em nível dos estados, para entender as respostas educacionais brasileiras à Covid-19.

Para tanto, foram consultadas 26 páginas web das secretarias estaduais de educação e uma página web do Distrito Federal, a fim de mapear e entender as respostas destes órgãos assumidas em nível educacional no contexto da Covid-19. Assim, os dados foram organizados a partir de parâmetros que permitiram compreender melhor as diretrizes emanadas destes órgãos, tais como: política institucional de oferta de Ensino Remoto Emergencial, tecnologias empregadas, política de acesso gratuito para alunos e professores e aproveitamento de materiais didáticos existentes ou criação de novos. Inicialmente, procurou-se informações sobre a adoção ou não de educação remota como procedimento para manter os vínculos entre estudantes e escolas.

Constatou-se que apenas o estado de Roraima não possuía informações sobre implementação de aulas remotas na educação básica devido à Covid-19. Não foi possível identificar alguma política que privilegiasse o vínculo: o foco de todas as iniciativas estava no conteúdo curricular, ou seja, na sua reposição e na reorganização de calendários escolares por meio da educação remota.

Entre os estados que iniciaram atividades remotas, apenas Alagoas não indicava o uso de videoaulas transmitidas por TV Aberta. Essas aulas ainda são depositadas em canais do Youtube. Com o objetivo de analisar o acesso aos vídeos, realizou-se levantamento das páginas do Youtube dos seguintes estados: Minas Gerais, São Paulo, Rio Grande do Sul e Pernambuco.

Ressalta-se que nos estados analisados os vídeos possuíam altos índices de acesso, chegando a números de visualizações próximos de um milhão apenas nas duas primeiras semanas após o lançamento da proposta. Na pesquisa realizada no intervalo entre 22 e 28 de maio de 2020 verificou-se que um vídeo de aula remota não ultrapassava 1000 visualizações. Esse dado revela um possível abandono da iniciativa de aulas remotas ofertadas pelos estados brasileiros.

Todos os estados e o distrito federal que ofertam educação remota possuem sítios web ou aplicativos para celular com conteúdo. Entretanto, verificou-se a existência de uma plataforma denominada Rede Escola Digital (desenvolvida em parceria pelos Instituto Natura, Fundação Lemann, Fundação Telefônica Vivo, Instituto Inspirare, Fundação Vanzolini). Esta 
plataforma, utilizada pela maioria dos estados brasileiros, não possui conteúdos escolares direcionados aos diferentes níveis ou componentes curriculares. A plataforma está, literalmente, vazia.

Há ainda indicativos de acesso aos materiais impressos, mas não há clareza sobre quantos jovens conseguiram tal acesso e quantos ficaram de fora.

Não há, ainda, informações sobre custos da implementação da educação remota. Vale ressaltar que existem, no mínimo, um canal público - a TV Escola - e outro vinculado a fundações privadas - Canal Futura - que transmitem de forma gratuita, há alguns anos, conteúdos educacionais em formato de vídeo e texto.

Por fim, verificou-se ainda que as políticas de educação remota emergencial não promoveram a participação da comunidade escolar. As ações foram publicadas nas páginas das secretarias de educação como ações do "executivo".

Pode-se afirmar que esse seja o maior equívoco, pois, ao não envolver professores $\mathrm{e}$ promover massificação da educação, por meio de transmissão massiva de videoaulas, as ações dos estados perdem no quesito mobilização da comunidade educativa envolvida nos processos ensino e aprendizagem.

Torna-se relevante ressaltar que os professores são referência na vida dos estudantes. A sua presença no espaço escolar ou na educação remota poderá contribuir para a manutenção dos vínculos afetivos entre professores e estudantes e entre os pares, e consequentemente, promover maior engajamento nas iniciativas didático-pedagógicas (UNESCO, 2020; MONTEIRO, 2020).

Nesse sentido, o levantamento realizado permitiu identificar um modelo de educação que privilegia a individualidade e não promove comunicação entre sujeitos. Uma página no Youtube não promove aproximação, os usuários, de modo geral, nem sempre são aqueles do círculo de convivência no ambiente escolar. Estas ações podem implicar em altos índices de evasão escolar, além disso, essa ausência aumentará as desigualdades na formação dos estudantes mais pobres que, ao não contarem com o professor nos processos ensino e aprendizagem, serão prejudicados em relação ao seu direito à educação.

\section{A importância da mediação pedagógica no Ensino Remoto Emergencial}

O levantamento bibliográfico realizado atestou que a maioria das iniciativas no Ensino Remoto Emergencial nos sistemas estaduais de educação no Brasil privilegiam a tecnologia, o equipamento e os meios de transmissão em detrimento da participação e do envolvimento dos 
sujeitos do processo educativo. Assim, constatou-se pouco investimento na mediação pedagógica - eixo norteador dos processos ensino-aprendizagem.

Para Masetto (2000), a mediação pedagógica é a atitude, o comportamento do professor que se coloca como motivador da aprendizagem, como mediador entre o estudante e o conhecimento, destacando o diálogo, a troca de experiências, o debate, a proposição de situações de aprendizagem e a afetividade nessas relações interativas, dialógicas.

Sobre essa questão, Vigotski (1998) afirma que nos tornamos humanos devido à nossa capacidade de utilizar instrumentos simbólicos para complementar a nossa atividade cognitiva. Nesse sentido, as propostas analisadas carregam uma concepção transmissiva de conteúdo, comum em períodos nos quais a interação era limitada devido às condições das tecnologias da época, televisão e rádio, por exemplo.

Com base num contexto no qual a premissa das tecnologias digitais contemporâneas é a troca de experiências e o diálogo, causa estranheza que iniciativas em educação remota abram mão dos recursos disponíveis atualmente, conforme indicado nos dados coletados.

A concepção de mediação presente nas propostas analisadas não envolve mediação entre os sujeitos, mas o uso técnico de equipamentos como suporte principal do ensino e da aprendizagem, que enfraquecem o papel do professor e fortalecem o uso de materiais préelaborados e apresentados de forma transmissiva.

Diante do exposto, não se sabe ainda quais serão as consequências da aplicação deste modelo, mas é possível reconhecer a fragilidade de propostas educacionais que priorizam os equipamentos em detrimento das pessoas. Apesar da urgência posta pela pandemia, as propostas de retorno por meio do ensino remoto apresentaram limitações quanto a um modelo pedagógico que privilegie a interação humana em detrimento da máquina, do objeto.

Já se passaram mais de 12 meses de pandemia e, apesar desta temporalidade significativa, não foram identificadas mudanças nos estados quanto ao modelo técnico implementado. Os desafios que se apresentam para a escola, portanto, já não se configuram apenas em um cumprimento de calendário e transmissão de conteúdos, mas demandam pensar em um modelo pedagógico que envolva os sujeitos do processo educativo, já que os desafios para o Brasil avançar na vacinação em 2021 indicam um retorno do ensino presencial mesclado ao ensino remoto. Ou seja, possivelmente este formato permanecerá por mais um ou dois anos. A manutenção do modelo técnico pode ser extremamente prejudicial para a educação brasileira.

Diante do exposto, a escola não pode, portanto, ser alijada de seu lugar de promoção do diálogo, da mediação e da construção de diferentes saberes. 
Trata-se de uma escola que, apesar da crise, permanece a mesma em seu aspecto social, pois reforça a sua importância junto aos estudantes e se consolida como instituição, lugar central para a formação de novas gerações.

\section{A Escola no Contexto da Pandemia da Covid-19: função social, desafios e perspectivas}

A implementação do Ensino Remoto Emergencial no contexto da pandemia da Covid19 reafirma a relevância da escola e a sua função social na contemporaneidade. Com base na revisão de literatura realizada, a escola surge historicamente como fruto da necessidade de se preservar e reproduzir a cultura e os conhecimentos da humanidade, crenças, valores e conquistas sociais, concepções de vida e de mundo, de grupos ou de classes. Ela permaneceu e se modernizou à medida que foi capaz de se tornar instrumento na produção de novos valores e crenças, na difusão e socialização de conquistas sociais, econômicas e culturais.

Pode-se afirmar que a escola pública, aberta e igualitária, desde a sua criação tem possibilitado a crianças, adolescentes e jovens o acesso aos saberes e aos bens culturais da humanidade. Por meio da escola, os sujeitos podem se perceber como partes integrantes de um todo social, situando-se em sua realidade histórico-social. Além disso, para os estudantes das comunidades populares, a escola tem sido espaço-tempo ímpar para fornecer recursos e possibilidades de luta contra a exclusão social.

Como instituição social, a escola está inserida no contexto histórico-social, numa realidade na qual pode exercer influências, e caracteriza-se como sendo uma escola democrática, uma instituição de cultura cujo papel é socializar os saberes, as ciências e as artes produzidas socialmente.

Para Libâneo (2012), o processo educativo que se desenvolve na escola por meio do ensino consiste na reconstrução de conhecimentos e experiências acumulados pelas gerações ao longo do desenvolvimento histórico-social. Assim, a finalidade do processo de ensinoaprendizagem é estimular a reconstrução dos conhecimentos sistematizados, das capacidades, das habilidades e das atitudes necessárias à aprendizagem, tendo em vista a preparação para o prosseguimento dos estudos, para o mundo do trabalho, para a família e para as demais exigências da vida social.

Uma abordagem sobre a escola originada na Sociologia da Educação busca, no entanto, aliar a análise externa da escola a ações internas. A proposta básica é defender a escola como espaço de vivências de novas relações sociais, ou seja, as formas como se organizam e ocorrem as relações sociais na escola aparecem como caminho pedagógico para a 
formação dos estudantes. A formação escolar estaria centrada não nos conhecimentos formais, mas no processo de sua aquisição e nas relações sociais aí desenvolvidas (CHARLOT, 2009; 2013; DUBET, 2011; 2008; 2004).

Trata-se de uma proposta que defende uma pedagogia cooperativa, ressaltando práticas de convivência entre professores e estudantes, voltada para problemas sociais que se passam fora da escola nas práticas sociais, entre eles, desigualdades, conflitos, questões tecnológicas, ambientais e doenças em geral, e no contexto atual, a pandemia da Covid-19. Nesse sentido, na abordagem sociocultural, as escolas são espaços-tempos para criação de situações pedagógicas interativas e problematizadoras. Esta abordagem acentua os fatores sociais e culturais no processo de conhecimento, contrapondo-se à ênfase nos conteúdos formais, ao enfoque psicológico da aprendizagem (FORQUIN, 1993; FRIGOTTO; CIAVATTA, 2003; FREIRE, 2004).

Pode-se afirmar que a instituição escola inserida na sociedade espelhará sempre as circunstâncias sociais, econômicas, científicas e culturais próprias de cada etapa da evolução das sociedades. Assim sendo, qualquer reflexão sobre a escola não pode deixar de considerar o contexto histórico-social de sua inserção.

Nesse sentido, o desafio que se coloca para a escola é o de responder não só aos estudantes que nela buscam um conjunto de saberes, mas também ao enorme desafio de formar sujeitos críticos e participativos. É na resposta positiva a este desafio que se verifica a função formativa da escola. De fato, numa sociedade em permanente evolução científica e tecnológica, responder ativamente às demandas de formação é algo complexo, que demanda planejamento dos profissionais da educação que atuam na escola (GOMES, 2014; 2017).

Este cenário complexo tenderá a ser atenuado com uma significativa articulação entre a escola e a comunidade, integrando sempre, e tanto quanto possível, os recursos e conhecimentos disponíveis por meio de parcerias em projetos com impactos positivos quer na escola, quer na comunidade. É, pois, neste contexto complexo, marcado pelo enfrentamento da pandemia da Covid-19, que o professor poderá desenvolver um trabalho que promova a formação dos estudantes e potencialize condições favoráveis para a análise crítica do que acontece no Brasil e no mundo e, além disso, inspirar entre os estudantes modos de pensar e de atuar ativamente nesse contexto de crise na saúde e na educação.

Coerente com essa perspectiva, verificou-se que a pandemia da Covid-19 tem provocado a retomada do sentido pedagógico da escola, e análise das demandas básicas de aprendizagem para a sobrevivência e para as necessidades básicas imediatas das pessoas. 
Trata-se de uma escola comprometida com a vida humana e com o desenvolvimento da cidadania dos estudantes.

Torna-se relevante investigar nesse cenário de crise: que respostas a escola dará? Para Silva (1996) e Apple (2010), currículo e escola podem ser instrumentos para problematização das questões sociais, políticas, econômicas e educacionais que nos afligem a fim de minimizar os efeitos indesejáveis na vida humana.

Em seus estudos sobre currículo escolar, Libâneo (2006; 2012) destacou que no quadro das políticas neoliberais para a escola resultam pelo menos dois modelos: o currículo instrumental, baseado numa pedagogia de resultados; e o currículo de promoção social, que valoriza a adoção de formas de organização das relações humanas, voltadas para a convivência e integração social. $\mathrm{O}$ autor verificou que a implantação desses currículos no Brasil resultou em pelo menos três tipos de organização curricular nos sistemas de ensino: os que conjugam esses dois modelos; os que focalizam mais o currículo instrumental e os que elegem o currículo de proteção social. A escolha de um desses modelos por parte dos sistemas escolares estaduais e municipais difere conforme preferências ideológicas e políticas dos dirigentes educacionais.

Pesquisas em educação sobre as políticas educacionais e políticas para a escola e a sala de aula defendem uma escola pública, obrigatória e gratuita organizada pedagogicamente e inclusiva. No entanto, quando se trata de transformar esse posicionamento em formas de organização, funcionamento da escola e em ações pedagógicas e didáticas, surgem divergências e desacordos.

Assim, pode-se afirmar que as abordagens sociocríticas divergem em relação aos objetivos da escola, à concepção de conhecimento e à maneira como se articulam os processos escolares e a diversidade social. O campo de disputas entre elas é demarcado por tensões existentes entre a exigência social e democrática de escolarização formal a todas as crianças, adolescentes e jovens e, ao mesmo tempo, a necessidade de as escolas se organizarem de forma adequada para o acolhimento da diversidade social e cultural expressa pelas diferenças individuais e sociais entre os estudantes (PIMENTA, 2013; LIBÂNEO, 2012).

Coerente com essa perspectiva, defende-se um currículo baseado no conhecimento crítico centrado na formação cultural e científica que realce a universalidade da cultura escolar, em razão do direito universal ao conhecimento. Essa opção implica em reconhecer que as práticas socioculturais que crianças, adolescentes e jovens compartilham na família, na comunidade e nas várias instâncias da vida cotidiana são, também, determinantes pela apropriação do conhecimento e pela formação da identidade pessoal e cultural. 
Como se vê, a crise provocada pela pandemia da Covid-19 evidencia, de certo modo, a crise da escola, e portanto, estimula a reinvenção desta instituição com base em três princípios: repensar a escola a partir de outras práticas sociais; conferir sentidos e significados às práticas docentes, considerando os desafios da vida e, ainda, pensar a escolar a partir de um projeto político pedagógico situado, pautado numa abordagem crítica que considere os desafios atuais e proponha a defesa da vida e dos direitos sociais.

\section{Considerações finais}

Procurou-se nesse artigo responder às seguintes questões de pesquisa: qual o nível de participação da comunidade escolar nas decisões sobre retorno remoto nas iniciativas dos governos estaduais brasileiros? Como a escola pode cumprir a sua função político-social no contexto de crise da pandemia da Covid-19? Verificou-se que a escola, por meio de seus professores, pode assumir um movimento de mudança e transgressão que demanda superar uma abordagem de escola passiva para assumir o compromisso com uma abordagem de escola que estimula o pensamento reflexivo e a problematização. E, assim, favorecer a formação de sujeitos críticos, autônomos, capazes de desafiar valores dominantes, construindo um território de relações, diálogos, confrontos e práticas, sendo assim espaço-tempo para estimular nos estudantes o compromisso com o desenvolvimento do seu país e de sua comunidade local.

Pelo exposto, pode-se afirmar que a escola tem papel fundamental na formação dos estudantes; entretanto, a pandemia da Covid-19 e o isolamento físico colocaram em pauta novos desafios. Torna-se relevante descobrir alternativas que possam ser mobilizadas, tendo em vista demandas pela reinvenção da escola a fim de que ela responda aos desafios da sociedade contemporânea.

Finalmente, verificou-se que os contextos da pandemia e do pós-pandemia da Covid19 instigaram o repensar crítico sobre a função social da escola. Nesse sentido, recomenda-se apenas o isolamento físico e não o isolamento social, e pressupõe ainda colocar em debate o exercício da prática educativa, revendo modos de organizar espaços-tempos, relações, conhecimentos, linguagens, metodologias e avaliação, ou seja, trata-se de um contexto provocativo que nos instiga a analisar os modos pelos quais o currículo e a docência podem ser reorganizados na e pela escola.

Concluindo, o convite para a retomada do papel da escola frente à pandemia da Covid19 no contexto contemporâneo é alerta para lembrar que outras crises virão; ainda, vale 
lembrar que a educação é campo de lutas, de articulação de forças, de posicionamentos, lembrando que as crises serão superadas/minimizadas por meio do diálogo, da participação do trabalho coletivo na escola, sempre em defesa da vida e das práticas inclusivas.

\section{REFERÊNCIAS}

APPLE, Michael Whitman. Global crises, social justice, and education. New York: Routledge, 2010.

ARRUDA, Eucídio Pimenta. Educação Remota Emergencial: elementos para políticas públicas na educação brasileira em tempos de Covid-19. Em Rede - Revista de Educação a Distância, Porto Alegre, v. 7, n. 1, p. 257-275, 2020. Disponível em: https://www.aunirede.org.br/revista/index.php/emrede/ article/view/621. Acesso em: 25 maio 2020.

ARRUDA, Eucídio Pimenta. Implementação das tecnologias digitais nos currículos das escolas de Educação Básica dos países membros da OCDE. In: SIQUEIRA, Ivan Claudio Pereira (org.). Subsídios à elaboração da BNCC: estudos sobre temas estratégicos da parceria CNE e Unesco. São Paulo: Moderna, 2018. Disponível em: https://fundacaosantillana.org.br/wp-content/uploads/2019/12/10_SubsidiosBNCC.pdf. Acesso em: 31 maio 2020.

BADIN, Ana Maria Andreola; PEDERSETTI, Simone; SILVA, Melisssa Borges da. Educação Básica em tempos de pandemia: tentativas para minimizar o impacto do distanciamento e manter o vínculo entre os alunos, as famílias e a escola. In: PALÚ, Janete; SCHÜTZ, Jenerton Arlan; MAYER, Leandro. Desafios da educação em tempos de pandemia. Cruz Alta: Ilustração, 2020, p. 123-137.

BARDIN, Laurence. Análise de conteúdo. Lisboa: Edições 70, 2011.

BAUMAN, Zygmunt. Em busca da política. Rio de Janeiro: Zahar, 2000.

CANDAU, Vera Maria. Educação escolar: entre o "sequestro" e a "reinvenção"? In:

CANDAU, Vera Maria; SACAVINO, Susana Beatriz. Educação: temas em debate. 1. ed. Rio de Janeiro: 7 Letras, 2015. p. 16-23.

CHARLOT, Bernard. A escola e o trabalho dos alunos. Sísifo. Revista de Ciências da Educação, n. 10, p. 89-96, set./dez. 2009. Disponível em: http://sisifo.ie.ulisboa.pt/index.php/ sisifo/article/view/165. Acesso em: 29 jan. 2020.

CHARLOT, Bernard. Da relação com o saber às práticas educativas. 1. ed. São Paulo: Cortez, 2013. 287 p.

COSCARELLI, Carla Viana. Navegar e ler na rota do aprender. In: Tecnologias para aprender. 1. ed. São Paulo: Parábola Editorial, 2016. cap. 4, p. 62-80.

COUTO, Edvaldo Souza; COUTO, Edilece Souza; CRUZ, Ingrid de Magalhães Porto. \#FIQUEEMCASA: EDUCAÇÃO NA PANDEMIA DA COVID-19. Educação, v. 8, n. 3, p. 
200-217, 2020. Disponível em: https://periodicos.set.edu.br/index.php/ educacao/ article/view/8777/3998. Acesso em: 10 jun.2020.

DUBET, François. Democratização escolar e justiça da escola. Educação Santa Maria, v. 33, n. 3, p. 381-394, set./dez. 2008. Disponível em:

https://periodicos.ufsm.br/reveducacao/article/view/1614/909. Acesso em: 20 maio 2020.

DUBET, François. Mutações cruzadas: a cidadania e a escola. Rev. Bras. Educ., Rio de Janeiro, v. 16, n. 47, p. 289-305, ago. 2011. Disponível em: http://www.scielo.br/scielo.php? script $=$ sci_arttext\&pid $=$ S1413-24782011000200002\&lng=pt\&nrm=iso. Acesso em: 22 maio 2020.

DUBET, François. O que é uma escola justa? Cadernos de Pesquisa, v. 34, n. 123, p. 539555, set./dez. 2004. Disponível em:

http://publicacoes.fcc.org.br/ojs/index.php/cp/article/view/4635. Acesso em: 21 maio 2020.

ESTELLÉS, Marta; FISCHMAN, Gustavo Enrique. Imaginando uma Educação para a Cidadania Global pós-Covid-19. Práxis Educativa, Ponta Grossa, v. 15, e2015566, 2020. Disponível em: https://www.revistas2.uepg.br/index.php/praxiseducativa. Acesso em: 11 jun. 2020.

FORQUIN, Jean-Claude. Escola e cultura: as bases sociais epistemológicas do conhecimento escolar. Porto Alegre: Artes Médicas, 1993.

FREIRE, Paulo. Pedagogia da tolerância. São Paulo: UNESP, 2004.

FRIGOTTO, Gaudêncio; CIAVATTA, Maria. Educação básica no Brasil na década de 1990: subordinação ativa e consentida à lógica do mercado. Educ. Soc., Campinas, v. 24, n. 82, p. 93-130, abr. 2003. Disponível em: https://www.scielo.br/pdf/es/v24n82/a05v24n82.pdf. Acesso em: 24 abr. 2020.

GARRIDO, Selma Pimenta. Políticas Públicas, Diretrizes e Necessidades da Educação Básica e Formação de Professores. In: LIBÂNEO, José Carlos; SUANNO, Marilza Vanessa Rosa; LIMONTA, Sandra Valéria. Qualidade da escola pública: políticas educacionais, didática e formação de professores. Goiânia: Ceped Publicações: Gráfica e Editora América: Kelps, 2013. p. $91-106$.

GATTI, Bernadete A. Possível reconfiguração dos modelos educacionais pós-pandemia. Estud. av., São Paulo, v. 34, n. 100, p. 29-41, dez. 2020. Disponível em http://www.scielo.br/ scielo.php?script=sci_arttext\&pid=S0103-40142020000300029\&lng=pt\&nrm=iso. Acesso em: 15 fev. 2021.

GATTI, Bernardete Angelina. Formação de professores no Brasil: características e problemas. Educ. Soc., Campinas, v. 31, n. 113, p. 1355-1379, Dec. 2010. Disponível em: http://www.scielo.br/scielo.php?script=sci_arttext\&pid=S010173302010000400016\&lng=en\&nrm=iso. Acesso em: 09 jun. 2020.

GOMES, Suzana dos Santos. Avaliação das capacidades de leitura. Educ. rev., Curitiba, n. 63, p. 221-236, mar. 2017. Disponível em: http://www.scielo.br/scielo.php? 
script=sci_arttext\&pid=S0104-40602017000100221\&lng=pt\&nrm=iso. Acesso em: 08 jun. 2020.

GOMES, Suzana dos Santos. Infância e tecnologias. In: COSCARELLI, Carla Viana. (org.). In: Tecnologias para aprender. 1. ed. São Paulo: Parábola Editorial, 2016. cap. 9, p. 145158.

GOMES, Suzana dos Santos. Um olhar sobre as práticas de avaliação na escola. Belo Horizonte: Mazza Edições, 2014.

GOMES, Suzana dos Santos; TAVARES, Rosilene Horta; MELO, Savana Diniz Gomes. Sociedade, educação e redes: luta pela formação crítica na universidade. Araraquara, SP: Junqueira \& Marin, 2019. 351 p.

HODGES, Charles. et al. The difference between emergency remote teaching and online learning. EDUCAUSE Review, Louisville, 2020. Disponível em:

https://er.educause.edu/articles/2020/3/the-difference-between-emergency-remote-teachingand-online-learning. Acesso em: 28 maio 2020.

LIBÂNEO, José Carlos. O dualismo perverso da escola pública brasileira: escola do conhecimento para os ricos, escola do acolhimento social para os pobres. Educ. Pesqui., São Paulo, v. 38, n. 1, p. 13-28, mar. 2012. Disponível em: http://www.scielo.br/scielo.php? script $=$ sci_arttext\&pid=S1517-97022012000100002\&lng=en\&nrm=iso. Acesso em: 09 maio 2020 .

LIBÂNEO, José Carlos. Sistema de ensino, escola, sala de aula: onde se produz a qualidade das aprendizagens? In: LOPES, A. C.; MACEDO, E. Políticas de currículo em múltiplos contextos. São Paulo: Cortez, 2006. p. 70-125.

MASETTO, Marcos Tarciso. Mediação pedagógica e o uso da tecnologia. In: MASETTO, Marcos Tarciso; BEHRENS, Marilda Aparecida; MORAN, José Manuel. Novas tecnologias e mediação pedagógica. Campinas: Papirus, 2000. p. 133-173.

MONTEIRO, Sandrelena da Silva. (Re)inventar Educação Escolar no Brasil em Tempos da Covid-19. Rev. Augustus, Rio de Janeiro, v. 25, n. 51, p. 237-254, jul./out. 2020. Disponível em: https://revistas.unisuam.edu.br/index.php/revistaaugustus/article/view/552. Acesso em: 10 fev. 2021.

NYC Department of Education. Coronavirus Update. 2020. Disponível em: https://www.schools.nyc.gov/school-life/health-and-wellness/coronavirus-update. Acesso em: 31 maio 2020.

PEREIRA, Alexandre de Jesus; NARDUCHI, Fábio; MIRANDA, Maria Geralda de. Biopolítica e Educação: os impactos da pandemia de Covid-19 nas escolas públicas. Rev. Augustus, Rio de Janeiro, v.25, n. 51, p. 237-254, jul./out. 2020.Disponível em: https://revistas.unisuam.edu.br/index.php/revistaaugustus/article/view/554. Acesso em: 12 mar. 2021.

QUEIROZ, Magali Aparecida Mendes de; VIEIRA, Vânia Maria Oliveira. Imbricações entre mediação, práticas pedagógicas e evasão: um estudo em representações. Revista Educação 
Online, Rio de janeiro, n. 31, p. 82-104, maio/ago. 2019. Disponível em: http://educacaoonline.edu.puc-rio.br/index.php/eduonline/article/view/514. Acesso em: 22 abr. 2020.

RADIO FRANÇA INTERNACIONAL. Teleschool opens in France. Disponível em: http:// www.rfi.fr/en/france/20200323-teleschool-opens-in-france-as-homework-takes-on-a-newmeaning-under-covid-19. Acesso em: 05 maio 2020.

RIBEIRO, Ana Elisa. Leitura, escrita e tecnologia: questões, relações e provocações. In: Tecnologias para aprender. 1. ed. São Paulo: Parábola Editorial, 2016. cap. 2, p. 31-42.

UNESCO. School Closures causeb by Coronavírus. Disponível em:

https://en.unesco.org/covid19/educationresponse. Acesso em: 28 maio 2020.

VIGOTSKI, Lev Semenovitch. A formação social da mente. Trad. José Cipolla Neto, Luis Silveira Menna Barreto, Solange Castro Afeche. 1998.

XIAO, Chunchen.; LI, Yi. Analysis on the Influence of Epidemic on Education in China. In: DAS, Veena; KHAN, Naveeda (Ed.). Covid-19 and Student Focused Concerns: Threats and Possibilities. 2020. Disponível em:

https://americanethnologist.org/features/collections/covid-19-and-student-focused-concernsthreats-and-possibilities/analysis-on-the-influence-of-epidemic-on-education-in-china. Acesso em: 01 maio 2020.

XINHUA NEWS AGENCY. China focus: schools start online courses as epidemic control postpones new semester. China, 17 fev. 2020. Disponível em:

http://www.xinhuanet.com/english/2020-02/17/c_138792006_2.htm. Acesso em: 31 maio 2020.

\section{Como referenciar este artigo}

ARRUDA, E. P.; GOMES, S. S.; ARRUDA, D. E. P. Mediação tecnológica e processo educacional em tempos de pandemia da COVID-19. Revista Ibero-Americana de Estudos em Educação, Araraquara, v. 16, n. 3, p. 1730-1753, jul./set. 2021. e-ISSN: 1982-5587. DOI: https://doi.org/10.21723/riaee.v16i3.14788

Submetido em: 20/10/2020

Revisões requeridas em: 12/11/2020

Aprovado em: $16 / 12 / 2020$

Publicado em: 01/07/2021 